\title{
A INFLUÊNCIA DA ORIENTAÇÃO EMPREENDEDORA NA CAPACIDADE ABSORTIVA E O DESEMPENHO DAS STARTUPS BRASILEIRAS
}

Daniel Penz ${ }^{1}$

Carlos Ricardo Rossetto ${ }^{2}$ Jonas Araújo Nascimento ${ }^{3}$

Bianca Amorim ${ }^{1}$

${ }^{1}$ Universidade do Estado de Santa Catarina - UDESC

${ }^{2}$ Universidade do Vale do Itajaí

${ }^{3}$ Instituto Federal de Educação, Ciência e Tecnologia do Ceará 


\section{A INFLUÊNCIA DA ORIENTAÇÃO EMPREENDEDORA NA CAPACIDADE ABSORTIVA E O DESEMPENHO DAS STARTUPS BRASILEIRAS}

Resumo: O ambiente de competição empresarial se intensifica a cada dia. Esse acirramento tem se dado, sobretudo, pelo incremento da velocidade na qual as mudanças acontecem, mais especificamente, na área da tecnologia da informação. Uma consequência desse fenômeno é o surgimento de novos tipos de empresas, como por exemplo, as startups. Este estudo teve o objetivo de verificar o relacionamento da orientação empreendedora, capacidade absortiva e o desempenho em startups brasileiras. A pesquisa coletou dados por meio de uma survey realizada a partir do banco de dados público da Associação Brasileira de Startups - ABSTARTUPS. A amostra foi composta de 155 empresas startups do Brasil. E evidenciou relacionamento entre a orientação empreendedora e a capacidade absortiva e tornou possível inferir a necessidade de melhoria nas ferramentas de avaliação de desempenho aplicadas a Startups, bem como a diferenciação nos modelos de aquisição de conhecimentos vivenciados no mercado.

Palavras-chave: Orientação empreendedora. Capacidade absortiva. Desempenho. Startups.

\section{Introdução}

É sabido que o ambiente de competição empresarial tem se intensificado a cada dia. Parte desse acirramento competitivo tem se dado pelo incremento, cada vez maior, na velocidade na qual as mudanças ocorrem, sobretudo no campo da tecnologia da informação. Tem-se, por exemplo, o surgimento de novos tipos de empresas como as startups - organizações com um alto grau de incerteza que, em muitas vezes, seu principal ativo é somente uma ideia. Nascem sem um modelo de negócio definido e já competindo internacionalmente.

No Brasil, o fenômeno das startups tem se revelado ainda mais forte na já conhecida veia empreendedora do brasileiro. De acordo com a pesquisa UHY (BBC, 2011), uma rede de consultores baseada em Londres, entre 2006 e 2010, o número de startups no Brasil cresceu em uma taxa de 7,2\% ao ano. Em 2012, foi constatada a existência de mais de 10.000 empreendimentos deste tipo, movimentando perto de R $\$ 2$ bilhões (PEGN, 2014). A criação de novas empresas é uma importante fonte de geração de

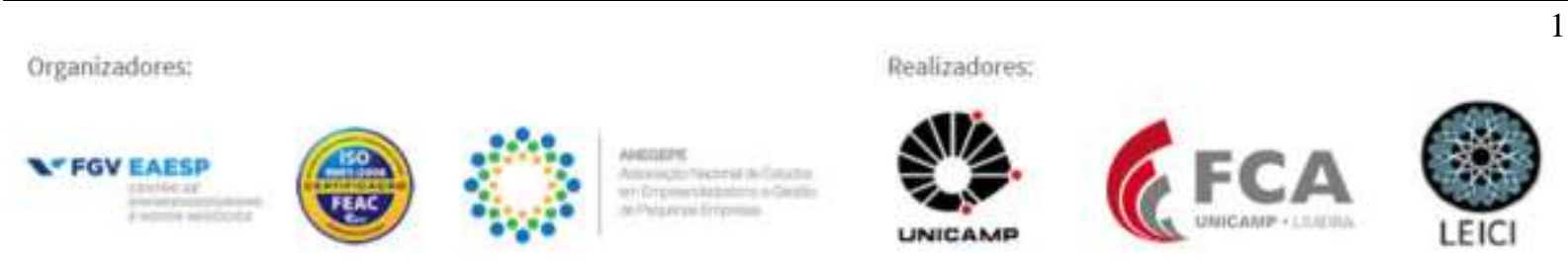


emprego, inovação e desenvolvimento. Mas para que esses empreendimentos tecnológicos aumentem suas chances de sucesso é fundamental que as startups consigam formular e implementar estratégias que lhes confiram uma vantagem competitiva sobre seus concorrentes. As startups podem desenvolver orientação empreendedora que pode ter um papel importante para ajudar as empresas a terem a preferência de consumidores com novos hábitos de consumo. Aliada a isso, as empresas deverão desenvolver uma habilidade de captar uma informação exterior, absorvê-la e, posteriormente, usá-la com fins comerciais, gerando desempenho superior. Definida por Zahra e George(2002) como capacidade absortiva.

A orientação estratégica é crítica para a sobrevivência de longo prazo das empresas com alto grau de desempenho. Para explicar esse fenômeno, várias orientações estratégicas têm sido usadas como por exemplo: a orientação para o mercado, orientação empreendedora, orientação para o aprendizado, orientação tecnológica, orientação para produto, orientação para recursos e orientação para consumidor (LEDWITH et al., 2009).

E destacado, por exemplo, que as empresas inseridas em ambientes tecnologicamente turbulentos recorrem a orientação para o empreendedorismo, com a finalidade de identificar e aproveitar oportunidades. Corroborando com esta linha, Li et al. (2008) salientam que há relação positiva entre orientação para o empreendedorismo e capacidades significativas para explorar as oportunidades resultantes da turbulência tecnológica.

Um tipo de organização que é própria de ambientes tecnológicos e extremamente turbulentos são as startups e identificar os fatores que influenciam o sucesso desse tipo de empresa complexa (PEÑA, 2002).

Um aspecto que demonstra a importância de se estudar os fatores críticos de sucesso das startups é a alta "taxa de mortalidade" presente nesse tipo de organização, sobretudo nos seus primeiros dois anos de existência, evidenciando a necessidade de estudos acerca do desempenho. Quanto maior a quantidade de informações obtidas, maior será o desenvolvimento das empresas nos seus primeiros anos de vida (PENA, 2002).

Há pesquisadores que têm enfatizado a necessidade de esclarecimento do papel da capacidade absortiva em diferentes contextos, como por exemplo, em países em desenvolvimento inclusive no setor de serviços (HARVEY et al., 2010).

Diante das justificativas apresentadas, tem-se então, o problema de pesquisa que este trabalho se propõe a responder: Qual a relação entre a capacidade absortiva, orientação empreendedora e o desempenho de empresas startups brasileiras? Pretende-se responder essa pergunta com atingindo o seguinte objetivo de trabalho.

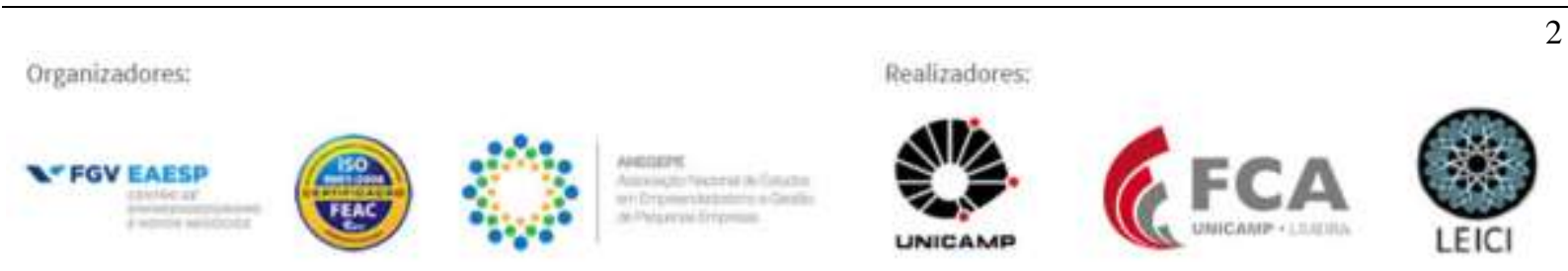




\section{Orientação empreendedora}

No contexto empresarial, orientação empreendedora (OE) surgiu como um conceito importante para investigar o espírito empreendedor das empresas e a sua influência sobre os processos estratégicos e desempenho (RAUCH et al., 2009).

O conceito de OE ganhou uma interpretação mais robusta a partir da contribuição de Miller (1983). Para o autor, a OE pode ser interpretada como uma característica das empresas que vão além do desempenho de um único indivíduo, sobretudo quando a estrutura da empresa aumenta e os processos se tornam mais complexos. Essa visão ajudou a despertar o interesse da academia pelo conceito.

Covin, Green e Slevin (2006) ampliam o conceito de OE. Segundo os autores, a orientação empreendedora é mais percebida como uma forma de gerenciamento da organização e não somente como uma característica de seus projetos empreendedores, sobretudo pelo gerenciamento do crescimento. Na visão de Teece (2007) o gerenciamento empreendedor de grandes empresas é uma capacidade importante para o crescimento rentável e durável, sobretudo em um contexto de inovação.

Considerando a operacionalização do constructo de orientação empreendedora, o trabalho seminal de Miller (1983) propôs uma maneira de reconhecer essas estratégias empreendedoras, no nível da firma, e identificou três dimensões: 1) inovatividade - a tendência da organização "de participar e apoiar novas ideias, a experimentação, a novidade e os processos criativos que podem resultar em novos produtos, serviços ou processos tecnológicos"; 2) Proatividade - relaciona-se com uma perspectiva de futuro, através da qual as empresas procuram, ativamente, antecipar oportunidades para desenvolver e introduzir novos produtos ou serviços no mercado, procurando obter vantagem competitiva (MILLER, 1983); e 3) Assunção de riscos - essa dimensão reflete a aceitação da incerteza e do risco das atividades conexas e normalmente é caracterizada pelo comprometimento de recursos e atividades incertas.

Mais tarde, Lumpkin e Dess (1996) apresentam uma proposta, construída a partir dos estudos de Miller (1983) e Covin e Slevin (1989), que adiciona mais duas dimensões ao conceito de $\mathrm{OE}$, ficando então com cinco dimensões. Os autores complementam que, nesse conjunto com cinco dimensões, é possível que haja variação independente uma da outra. As duas dimensões que os autores somaram foram: a agressividade, que é a tendência a agir de forma agressiva em relação aos concorrentes; e a autonomia, que tem a ver com a proatividade da empresa para as oportunidades de mercado.

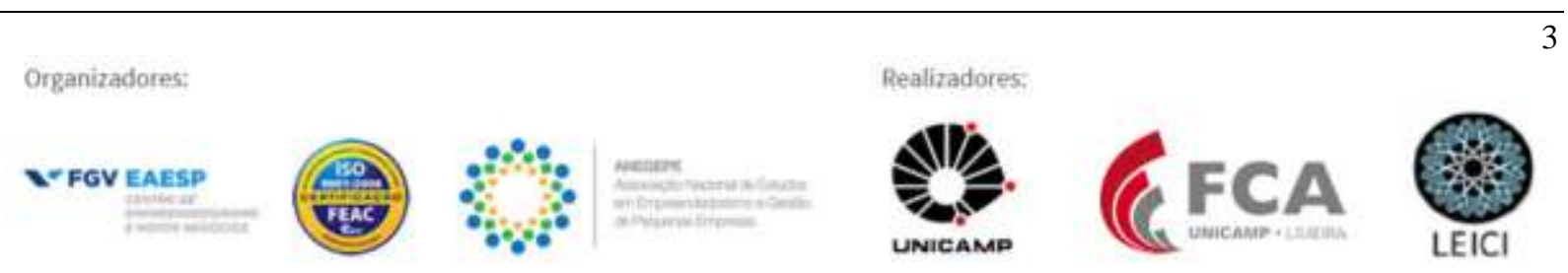


Para esta pesquisa, será levada em consideração a classificação feita por Lumpkin e Dess (1996). Segundo esses autores, a orientação empreendedora de uma organização é dividida em cinco dimensões. A saber: inovatividade, assunção de riscos, proatividade, autonomia e agressividade. Ainda segundo os autores, a importância de cada dimensão para predizer a natureza e o sucesso de um empreendimento depende de fatores externos, fatores internos, ou ainda, de características dos fundadores ou dos líderes da organização, podendo a OE ser constituída por diferentes combinações das cinco dimensões, ou mesmo por apenas algumas delas. Na sequência apresentamos as cinco dimensões da orientação empreendedora.

\subsection{Inovatividade}

A inovatividade é, para Lumpkin e Dess (1996), a tendência, da organização, em engajar e apoiar novas ideias, novidades, experimentos e processos criativos, que podem ter como consequência, novos produtos, serviços ou processos. Ela retrata o esforço em encontrar novas oportunidades e modernas soluções (DESS; LUMPKIN, 2005), envolvendo criatividade e experimentação.

A definição de inovação de Schumpeter (1982) se assemelha ao que foi dito no parágrafo anterior. Os experimentos têm a ver como a realização de novas combinações, quer sejam produtos, processos, mercados ou matérias-primas.

Quanto ao grau de inovatividade de uma organização, segundo a literatura, há diversas formas de identificá-lo. Para tanto, considera-se, por exemplo, o montante financeiro investido em inovação, os recursos humanos dedicados às atividades de inovação, o número de novos produtos ou de serviços lançados, ou ainda a frequência de mudança em linhas de produtos ou serviços, entre outras (COVIN; LEVIN, 1989).

\subsection{Assunção de riscos}

Assumir riscos está relacionado com o comportamento de empenhar grandes volumes de capital, expondo a empresa, com objetivo de buscar de grandes oportunidades de mercado, tendo em vista altas taxas de retorno (LUMPKIN; DESS, 1996).

A organização e os seus executivos, segundo Dess e Lumpkin (2005) estão expostos a três tipos de riscos: riscos de negócio, riscos financeiros e risco pessoal. $\mathrm{O}$ risco de negócio é lançar-se no desconhecido sem ter conhecimento da probabilidade de sucesso entrar em mercado não testado, por exemplo; Riscos financeiros estão relacionados à exigência da empresa precisar tomar emprestada grande soma de recursos tendo em vista o seu crescimento - o dilema risco e retorno; o risco de pessoal está relacionado a tomada de decisão do executivo quando este resolve adotar um padrão na buscar executar uma determinada estratégia.

\subsection{Proatividade}

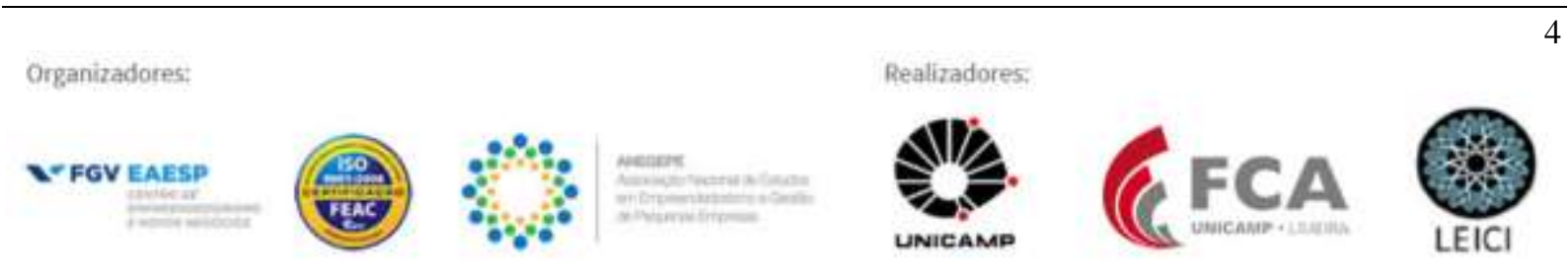


Ter proatividade tem a ver com antecipação de movimentos. Segundo Lumpkin e Dess (1996), a proatividade guarda relação com ações que tenham a finalidade de antecipar e perseguir novas oportunidades e também de acessar novos mercados. É possível que a organização também interfira no ambiente, moldando-o.

Uma organização proativa busca novas oportunidades que podem ou não estar relacionadas a sua atual linha de atuação, lança marcas e produtos novos antes da concorrência e pode eliminar, estrategicamente, uma operação em estágio de maturidade ou no declínio do seu ciclo de vida.

Segundo a proposição de Miller (1983) e Covin e Slevin (1989), para se avaliar o grau de proatividade de uma organização é necessário considerar sua propensão em estar à frente no mercado, desenvolvendo novos produtos e tecnologias ou serviços, em vez de simplesmente ir na onda do mercado. Para isso, as organizações proativas monitoram tendências, identificam futuras necessidades dos clientes e antecipam mudanças relativas a demandas ou problemas emergentes que podem levar a novas oportunidades de negócios (DESS; LUMPKIN, 2005).

\subsection{Autonomia}

O processo empreendedor tem a característica muito forte que é a autonomia.). Lumpkin e Dess (1996) afirmam que a liberdade para agir de forma independente e para tomar decisões é fundamental para a autonomia e, consequentemente, para o processo empreendedor. Miller (1983) relaciona o nível de empreendedorismo organizacional à existência de líderes mais autônomos.

Com relação ao nível de autonomia das organizações os autores afirmam que organizações com uma forte cultura que promove a ação independente e a busca de oportunidades sem o constrangimento social são caracterizadas por terem um alto nível de autonomia.

Dess e Lumpkin (2005) corroboram com essa ideia quando afirmam que o pensamento empreendedor deve ser encorajado nas pessoas da organização com a finalidade de desenvolver a dimensão autonomia.

Os traços e ou evidências de autonomia nas empresas podem variar em função de três atributos: tamanho da organização, estilo gerencial ou propriedade. Segundo Miller (1983) em pequenas empresas, grande parte da atividade empreendedora é associada a gestores que centralizam a autoridade e que lideram o conhecimento da organização, atentos a tecnologias e mercados emergentes.

\subsection{Agressividade competitiva}

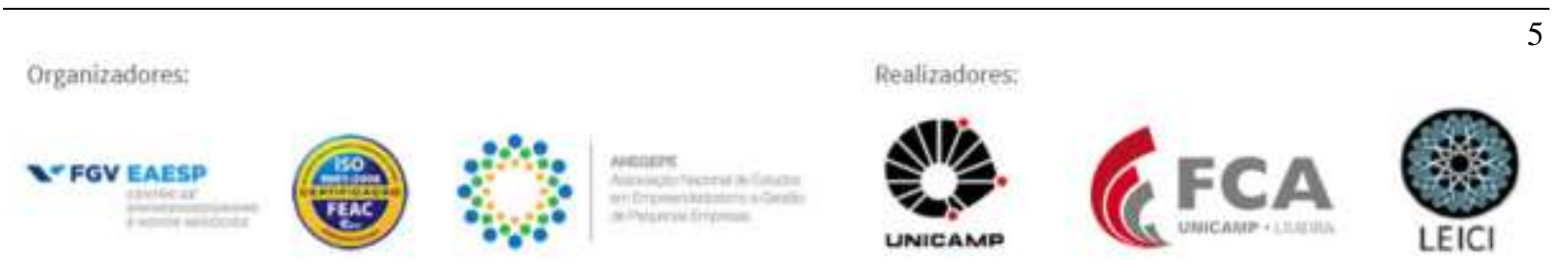


A agressividade competitiva é a propensão da organização em desenvolver ações competitivas para desafiar os seus competidores, direta ou indiretamente, alcançando melhores posições no mercado no intuito de superá-los (STAMBAUGH et al., 2009).

Covin e Slevin (1989) e Covin e Covin (1990) tratam a agressividade competitiva como parte da proatividade. Embora essas duas dimensões sejam fortemente relacionadas, Lumpkin e Dess (2001) apontam que a proatividade é uma resposta a oportunidades, ao passo que a agressividade competitiva é uma resposta a ameaças. Os autores afirmam que essas dimensões podem ocorrer sequencialmente e dinamicamente em uma organização.

A visão de Venkatraman (1989) sobre a agressividade competitiva é mais na alocação de recursos para ganhar posições em determinado mercado de forma mais rápida que os competidores. Essa agressividade pode ser baseada em inovação de produto, desenvolvimento de mercado, alto investimento para melhorar participação no mercado, entre outros. Ainda segundo o autor, a agressividade competitiva reflete a noção de explosão, isto é, o aumento da posição competitiva em pouco tempo, a estratégia de multiplicação e a perseguição de parte do mercado, como um importante caminho para atingir a rentabilidade. As evidências de agressividade competitiva podem ser alcançadas ao avaliar-se, por exemplo, a postura gerencial em termos de competitividade (COVIN; COVIN, 1990).

\section{Capacidade Absortiva}

O conceito de capacidade absortiva (CAP) foi definido pela primeira vez por Cohen e Levinthal $(1989 ;$ 1990). Em 1989, os autores cunharam o conceito como sendo a habilidade para identificar, assimilar e explorar o conhecimento externo. No ano seguinte, esses mesmos autores expandiram a definição para a capacidade da empresa de reconhecer o valor de uma nova informação, advinda de fontes externas, de assimilá-la e de aplicá-la com fins comerciais, de forma estratégica e com base na inovação, propondo um modelo (COHEN; LEVINTHAL, 1990).

Ainda segundo Cohen e Levinthal $(1989 ; 1990)$ a capacidade da empresa para adquirir conhecimento de seu ambiente externo e um subproduto de seu próprio processo de pesquisa e desenvolvimento $(\mathrm{P} \& \mathrm{D})$.

Segundo os mesmos autores, a contribuição de Cohen e Levinthal $(1989 ; 1990)$ se deu num acréscimo à literatura de um rico conjunto de explicações sobre os vários fatores determinantes da vontade de uma empresa em investir em capacidade de absorção. Esse conjunto de explicações é composto pelo alcance das oportunidades tecnológicas disponíveis para a empresa; a natureza da oportunidade tecnológica - básica versus aplicada; e o grau de melhora do desempenho tecnológico através do uso de conhecimento externo.

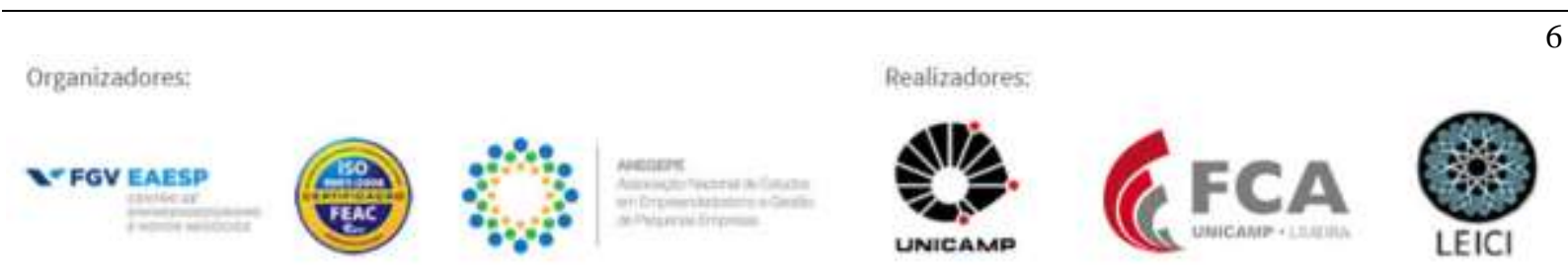


Além disso, Cohen e Levinthal (1989; 1990) sugerem que o desenvolvimento de Capacidade Absortiva de uma organização está ligada com os investimentos realizados nas capacidades de absorção dos seus membros, apresentando uma tendência de se desenvolver cumulativamente e não guardar dependência com a sua trajetória, além de depender da capacidade da organização de compartilhar conhecimento e comunica-lo internamente. Estas características salientam o caráter estratégico desta capacidade dinâmica, bem como a sua relação com os demais recursos e capacidades.

Lane e Lubatkin (1998) redefiniram o modelo proposto por Cohen e Levinthal (1989; 1990), propondo uma nova construção para avaliar a capacidade absortiva relativa. A principal diferença de construção da teoria original é no contexto da análise. No lugar de analisar o setor no qual estão inseridas as organizações, os autores analisaram a capacidade das empresas de absorver o conhecimento de outras organizações.

Os autores sugerem que o conceito de capacidade absortiva apresenta associação com o ambiente de conhecimento, como existindo uma coevolução mútua. De forma que o nível de capacidade absortiva de uma empresa é dependente do ambiente no qual ela está inserida e também do quão forte é essa inserção no meio, de tal maneira que havendo mudanças no ambiente, a empresa responde de modo a renovar esta relação, adaptando-se às novas condições que o ambiente lhe apresenta.

Apesar do crescimento das pesquisas sobre a capacidade absortiva, o estudo desse constructo oferece dificuldade devido a sua ambiguidade e diversidade de definições, componentes, antecedentes e resultados (ZAHRA; GEORGE, 2002). Os autores postulam que a capacidade absortiva está dividida em dois conjuntos: a capacidade absortiva potencial - PACAP, onde estão localizados os processos de aquisição e assimilação do conhecimento e, em seguida, a capacidade absortiva realizada - RECAP, tendo como seus componentes os processos de transformação e aplicação do conhecimento para fins comerciais.

A capacidade absortiva potencial é a disposição da organização em adquirir e assimilar novos conhecimentos externos e capacidade absortiva realizada já é a habilidade da organização em transformar e aplicar estes novos conhecimentos. Para Zahra e George (2002), é a capacidade absortiva potencial que dá a firma flexibilidade estratégica e graus de liberdade para ela se adaptar e se envolver em ambientes extremamente velozes.

Os estudos de Todorova e Durisin (2007) sobressaem-se na literatura. Os seus estudos reforçam a definição de capacidade absortiva como sendo a habilidade da organização em reconhecer o valor das novas informações, assimilá-las, e aplica-las para fins comerciais. 
Esse destaque se dá em função de importantes proposições de alteração no modelo de Zahra e George (2002).

Uma definição de capacidade absortiva que podemos destacar é a de Camisón e Forés (2010). Segundo os autores, é a capacidade sistemática e dinâmica existente entre os dois subconjuntos da capacidade de absorção potenciais e realizados. Os autores destacam ainda que a capacidade absortiva se tornou uma das mais importantes construções nos últimos vinte anos, fundamentalmente porque os recursos de conhecimento externo são extremamente importantes.

Essa importância da capacidade absortiva é reforçada por Van Wijk et al. (2011) quando afirmam que ela influencia a inovação em três aspectos: velocidade, amplitude e frequência. Para os autores, a capacidade da organização de reconhecer o valor de conhecimentos externos novos, assimilá-los e aplicá-los, torna a capacidade de absorção uma das construções de alta relevância nas pesquisas acadêmicas organizacionais.

\section{Metodologia}

Esta pesquisa e norteada pela abordagem quantitativa, de caráter explicativo, utilizandose da técnica survey. Os dados foram coletados em campo uma única vez, caracterizando o estudo como tendo um corte do tipo transversal (cross-sectional), seguindo as recomendações de Malhotra (2001) e Hair Jr. et al. (2005).

$\mathrm{O}$ instrumento de pesquisa, escolhido em função da literatura revisada, passou por três processos de avaliação. No primeiro momento, dois pesquisadores estudiosos dos temas abordados neste estudo verificaram se a linguagem usada, em termos de estilo e das expressões textuais, estava alinhada com os constructos que foram medidos. O segundo passo da avaliação foi realizado por um investidor-anjo. Segundo a instituição Anjos do Brasil, um investidor-anjo é normalmente um (ex-) empresário/empreendedor ou executivo que já obteve sucesso em seus negócios, acumulando experiência e recursos financeiros suficientes para investir - normalmente entre 5\% a $10 \%$ do seu patrimônio - em novas empresas. Por último, foi realizado um pré-teste com empreendedores de startup da cidade de Sobral/ CE.

O pré-teste foi realizado com os empreendedores de startup, pelo critério da conveniência. Ressalta-se que os participantes do pré-teste guardavam similaridade com a população investigada e posteriormente foram excluídos da amostra. Nesta etapa, não foram detectados problemas de compreensão ou de inadequação de linguagem. Importa destacar que, entre todas as avaliações até o pré-teste, foram elaboradas dez versões do instrumento. O principal objetivo do procedimento exposto acima foi avaliar a aplicabilidade do instrumento, identificar e corrigir futuras falhas, como preconiza Malhotra (2001). 
O questionário foi composto de quatro seções: a $1^{\mathrm{a}}$, com 7 questões, era a caracterização da empresa; a $2^{\text {a }}$, composta por uma questão com 25 itens para avaliação, trazia o tema de orientação estratégica, com os itens abrangendo as quatro orientações (orientação empreendedora, orientação para o mercado, orientação tecnológica e orientação para o aprendizado); a $3^{\text {a }}$, era composta de uma questão com 8 itens, continha os itens de capacidade absortiva e por último, a seção de indicadores de desempenho (variação do faturamento no ano de 2016 e acréscimo do número de funcionários durante o ano de 2016) e a $4^{\mathrm{a}}$, com 4 questões sobre características do modelo de negócio da empresa e última questão sobre outras medidas e ou indicadores de desempenho usadas pela empresa. $\mathrm{O}$ instrumento era composto de 46 itens que solicitavam (embora a resposta não fosse obrigatória) o posicionamento do respondente. A primeira e quarta seção eram questões abertas ou de múltipla escolha. A segunda e terceira seções eram medidas por uma escala do tipo Likert de cinco pontos, variando de 1 (discordo totalmente) a 5 (concordo plenamente). As escalas Likert oferecem a possibilidade do respondente de escolher a intensidade de sua assertiva de acordo com o assunto abordado. Esta pesquisa fez uso de escalas já testadas anteriormente. As modificações realizadas tiveram como intuito adequar a linguagem ao objeto de estudo. Segundo Beal e Dawson (2007) as escalas com muitas categorias ou opções de resposta apresentam a tendência de levar a maiores vieses. Uma escala de cinco pontos pode diminuir consideravelmente esse efeito indesejado pois torna mais confortável e precisa a posição do respondente.

Para medir o constructo de orientação empreendedora tomou-se como base a escala adaptada e utilizada por Padrão (2011), no contexto das empresas de base tecnológica brasileiras. Originalmente, a escala foi desenvolvida por Hult, Ketchen e Arrfelt (2007) que por sua vez, se basearam no trabalho de Covin e Slevin (1989). As assertivas de Hult, Ketchen e Arrfelt (2007) estão no formato adequado à escala deste trabalho, por isso não se utilizou a escala original de Covin e Slevin (1989). Esse procedimento foi realizado tendo em vista ter uma escala que medisse da maneira mais abrangente possível as dimensões do constructo de orientação empreendedora e que não implicasse em um elevado número de itens.

Com relação ao desempenho de startups - variável dependente - serão usadas como medidas de desempenho o crescimento em vendas, medida usada por García-Muiña e NavasLópez (2007) e Mallick e Schroeder (2005) que é representado pela taxa de crescimento do faturamento, e o número de funcionários. Essa escolha foi feita para contemplar 
aquelas startups que já apresentam faturamento, bem como as que não faturam, mas, de alguma forma, tenham feito contratações para aumentar a sua equipe.

Neste estudo, o universo considerado são as startups brasileiras. Como referencial de população, foi tomado o número de empresas cadastradas no Startupbase, que é o banco de dados público da Associação Brasileira de Startups (ABSTARTUPS). A ABSTARTUPS e uma organização sem fins lucrativos, fundada em 2011, que tem como objetivo representar as startups brasileiras. Segundo a própria entidade, o Startupbase foi criado para mapear o ecossistema de startups brasileiras, conectando empreendedores, investidores, mentores, incubadoras, aceleradoras e agentes de fomento. Sua base de dados consta de mais de 20 mil perfis de pessoas e empresas. Já o número de startups informado pela entidade é de 4230, com representantes de todos os estados brasileiros.

Cadastradas no Startupbase, há empresas dos mais diversos modelos de negócio como assinaturas, B2B, B2C, C2C, Marketplace entre outros; dos mais diversos setores como agronegócio, biotecnologia, comunicação e mídia, construção civil, educação, entretenimento, eventos e turismo, finanças, games, hardware, internet, logística, meio ambiente, mobile, moda e beleza, nanotecnologia, SaaS (Web App), saúde, TIC e Telecom, varejo e e-commerce.

A pesquisa foi direcionada, em seu primeiro momento, às empresas cadastradas no banco de dados da ABSTARTUPS. Embora a associação divulgue que exista em sua base mais de 4.000 associados, a mineração de dados no Startupbase retornou somente 1548 contatos com endereços de e-mail únicos. Algumas empresas não possuíam todos os dados necessários para que fosse possível entrar em contato. Além do uso de ferramentas de email marketing, acionou-se alguns agentes do ecossistema de startups: aceleradoras, incubadoras, professores e hubs de inovação como o HUBINE, que é espaço criado pelo Banco do Nordeste do Brasil para fomentar o desenvolvimento de startups.

Ao todo foram 224 respondentes. Em seguida, usou-se o Microsoft Excel para tratar os dados. Foram excluídos 51 registros por estarem em branco ou incompletos; 3 por terem o preenchimento atípico (todos os campos tinham o mesmo valor); 12 porque as startups foram fundadas fora do período de interesse (startups fundadas até dezembro de 2016) e 3 porque o número de funcionários destoava sobremaneira do restante da amostra (as três tinham 50, 90 e 110 funcionários). A base ficou com 155 casos válidos.

\section{Procedimentos de Análise e Primeiros Resultados}

O primeiro procedimento foi a escolha do pacote estatístico SmartPls 3.0. Para manutenção ou exclusão das cargas fatoriais foi utilizado o critério estabelecido por Hair et al, (2005, p. 592) " Como uma carga significante poderia ainda ser relativamente fraca, uma

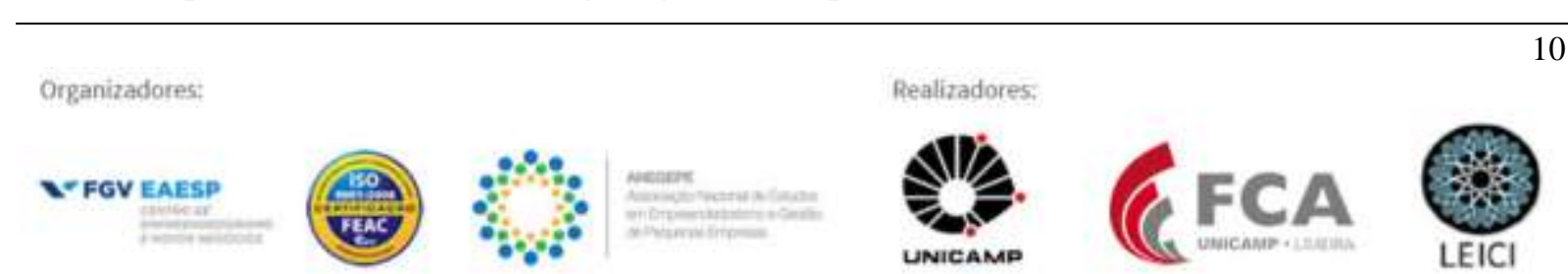


boa prática é que estimativas de cargas padronizadas devem ser de 0,5 ou mais, e idealmente de 0,7 para cima", porém em no modelo proposto as variáveis abaixo de 0,7 foram excluídas para obtermos o modelo ideal. Na próxima etapa foi avaliada: validade convergente; Alfa de Cronbach (AC); e Confiabilidade Composta (CC).

A Validade Convergente (VC) é calculada através da Variância Média Extraída (AVE), o valor da AVE precisa ser superior a 0,5 (HAIR Jr. et al. 2014). Como pode-se observar na tabela 2, todos os valores para AVE foram superiores a 0,5, com exceção da variável dependente que representa os 2 tipos de desempenho encontrados na teoria acerca de startups, desta maneira é possível afirmar que o modelo possui validade convergente.

Quanto a consistência interna do modelo, utilizou-se o Alfa de Cronbach (AC) e a Confiabilidade Composta (CC). Esses índices são utilizados para verificar se a amostra está livre de vieses ou analisar se as respostas em seu conjunto são confiáveis (SILVA, 2015). Pode-se observar na tabela 1 que os valores do AC variam entre 0,70 e 0,91 o que indica uma classificação moderada a alta. No que se refere a CC, os indicadores no entendimento de Hair et al. (2014) devem ser superiores a 0,7 o que se confirmou com exceção novamente da variável dependente.

Tabela 1 - Indicadores de ajuste, validade convergente e confiabilidade dos construtos

\begin{tabular}{ccccc}
\hline Constructo & AVE & $\begin{array}{c}\text { Confiabilidade } \\
\text { Composta }\end{array}$ & $\mathbf{R}^{2}$ & $\begin{array}{c}\text { Alpha } \\
\text { Cronbach }\end{array}$ \\
\hline $\begin{array}{c}\text { Orientação } \\
\text { Empreendedora }\end{array}$ & 0,62 & 0,83 & & 0,70 \\
Capacidade Absortiva & 0,56 & 0,86 & 0,38 & 0,80 \\
Desempenho & 0,45 & 0,45 & 0,02 & 0,91 \\
\hline
\end{tabular}

O maior VIF encontrado foi de 2,04

Fonte: dados da pesquisa.

A etapa subsequente se trata da determinação do coeficiente de Pearson $\left(\mathrm{R}_{2}\right)$ que avalia a porção da variância das variáveis endógenas, explicada pelo modelo estrutural. Este coeficiente aponta a qualidade do modelo ajustado, sendo sua interpretação para os valores de 0,75 substancial, de 0,50 moderado e de 0,25 fraco para as ciências exatas (HAIR et al., 2014; SILVA, 2015). Observa-se na tabela 1 que os valores do $\mathbf{R}^{2}$ se classificam com inclinação a moderada capacidade explicativa entre a relação Orientação Empreendedora para com a Capacidade Absortiva, enquanto que o valor do R2 entre capacidade absortiva e desempenho foi de 0,02 o que denota muito fraca ou ausência de capacidade de explicação do desempenho por parte do modelo proposto.

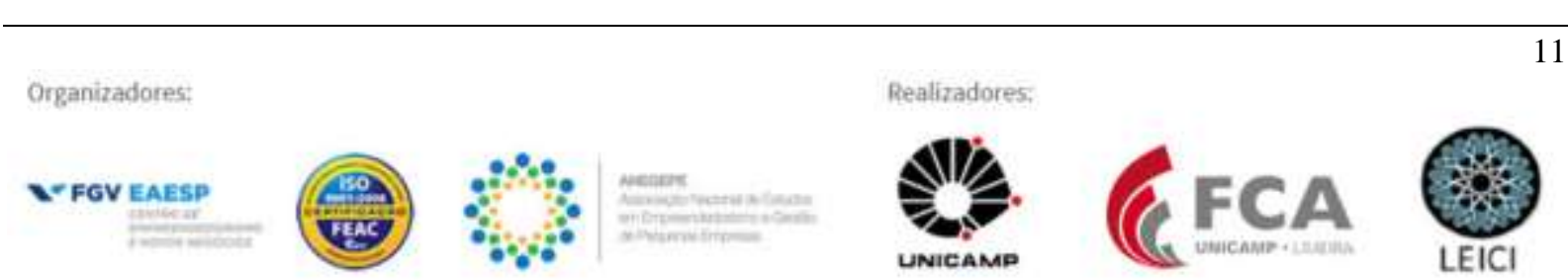


O próximo passo compreende a realização do Teste $t$ Student e dos Coeficientes de Caminho (Г). Silva (2015) pondera que para se aferir o teste $t$ Student realiza-se o cálculo entre as amostras originais de cada variável ou constructo e as respectivas amostras obtidas pelas técnicas de reamostragem (bootstrapping). Os valores acima de 1,96 são considerados significantes a $5 \%$ ou 0,05 , em que os construtos são relacionados e independentes.

Tabela 2 - coeficientes estatísticos

\begin{tabular}{cccccc}
\hline Relação & $\begin{array}{c}\text { Coeficiente de } \\
\text { Caminho }\end{array}$ & Desvio & Teste T & $\begin{array}{c}\text { p- } \\
\text { Valor }\end{array}$ & Resultado \\
\hline $\begin{array}{c}\text { Orientação } \\
\text { Orientadora -> }\end{array}$ & 0,62 & 0,10 & 1,33 & 0,00 & $\begin{array}{c}\text { Relação } \\
\text { Significante } \\
\text { Capacidade Absortiva }\end{array}$ \\
$\begin{array}{c}\text { Capacidade Absortiva -> } \\
\text { Desempenho }\end{array}$ & $-0,13$ & 0,07 & 9,42 & 0,18 & $\begin{array}{c}\text { Relação } \\
\text { insignificante }\end{array}$ \\
\hline
\end{tabular}

Fonte: dados da pesquisa.

Visualiza-se na tabela 2 um coeficiente de caminho robusto e significante evidenciando a relação da orientação empreendedora e da capacidade absortiva nas startups estudas, porém algo distinto ocorreu com a relação de Capacidade Absortiva e o Desempenho evidenciando que os modelos teóricos disponíveis ou ora os utilizados ainda não são capazes de estabelecer a relação entre as variáveis.

$\mathrm{Na}$ sequência verificou-se a Validade Preditiva $\left(\mathrm{Q}_{2}\right)$ e o Tamanho do efeito ( $\left.\mathrm{f}_{2}\right)$. A Validade Preditiva $\left(Q_{2}\right)$ de acordo com Hair et al. (2014) avalia a precisão do modelo ajustado. No entendimento do autor a validade preditiva tem que apresentar valores maiores que zero, os valores oriundos dos relacionamentos propostos neste estudo possuem valores superiores a zero, o que denota seu alinhamento com a literatura.

No que se refere ao Tamanho do Efeito (f2), ou Indicador de Cohen, para Hair et al. (2014) ele é obtido pela inclusão e exclusão de constructos endógenos do modelo, sendo que se realiza a avaliação de quanto cada constructo é útil para o ajustamento do modelo conceitual. Para interpretação desse coeficiente, entende-se como valores próximos de 0,02 para pouca utilidade, 0,15 de utilidade moderada e 0,35 com grande utilidade. Observa-se que o relacionamento entre os construtos Orientação Empreendedora e Capacidade Absortiva possuem grande efeito um sobre o outro e com capacidade preditiva.

Tabela 3 - Validade Preditiva e Indicador de Cohen

\begin{tabular}{lll}
\hline Relação & $\mathbf{Q}^{2}$ & $\mathbf{f}^{2}$ \\
\hline
\end{tabular}

Organizadores

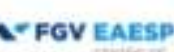

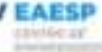

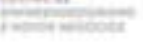
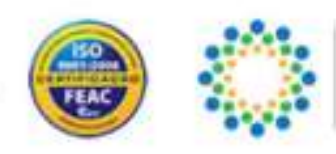

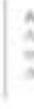

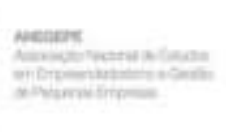

Realizadores:
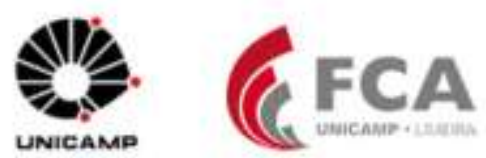


\begin{tabular}{ccc}
\hline $\begin{array}{c}\text { Orientação } \\
\text { Orientadora -> } \\
\text { Capacidade Absortiva } \\
\text { Capacidade Absortiva -> } \\
\text { Desempenho }\end{array}$ & 0,19 & 0,62 \\
\hline
\end{tabular}

Fonte: dados da pesquisa

\section{Discussão dos Resultados e Conclusões}

Neste estudo se verificou o relacionamento entre a orientação empreendedora e a capacidade de absorção conforme apresentado na sessão de resultados, porém algumas características chamam a atenção, se tratando de Orientação Empreendedora, as empresas se declararam como pesquisadoras de desenvolvimento e liderança tecnológica. Dentro dos fatores que promovem o crescimento das comunidades de startups definiram se como ágeis na introdução de novas tecnologias em suas operações e ousada em seus esforços para maximizar a chance de aproveitar as oportunidades o que corrobora o preconizado por Hult, Ketchen e Arrfelt (2007). De certo modo esperava-se que as empresas tomassem decisões e que fossem líder de seus mercados e assumissem projetos de alto risco desde que visualizassem alto retorno, porém estás características não estão presentes na comunidade de startups, o que nos leva a inferir que nossas ideias ainda estão voltadas em sua ampla maioria para os mercados locais e de projetos de baixo risco associado.

Para o construto capacidade absortiva apresentou um excelente ajuste ao modelo, porém algumas dimensões preconizadas por Zahra e George (2002) não foram reconhecidas como parte da sua atividade pelos entrevistados entre elas a busca de informações relevantes sobre o negócio em que atuam e a expectativa da gestão de que seus empregados busquem espontaneamente o conhecimento necessário, inclusive com fontes externas. O que demostra que o corpo funcional ainda carece de incentivos constantes para que se motive e realize atividades além das funcionais. Por outro lado, a organização parece não cobrar este tipo de política, pois não foi reconhecida a necessidade da administração de reuniões periódicas para compartilhamento de ideias, conceitos e realizações, porém em nossa perspectiva este fato se deve ao porte das empresas que ainda são pequenas e acreditam que sua comunicação informal supra este tipo de compartilhamento.

A agilidade está presenta para o compartilhamento sem a exigência formal. As organizações creem que seus funcionários sabem discernir oportunidades $\mathrm{e}$ utilizar conhecimentos coletados de maneira informal em suas estruturas, criando assim novas oportunidades através de conexões de conhecimentos pré-existentes com os comunicados informalmente. As organizações dão liberdade e apoiam novos testes
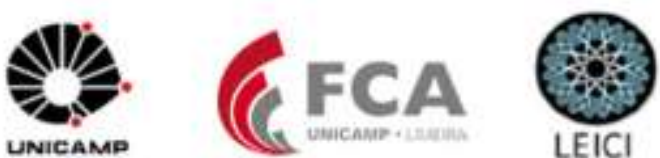
tecnológicos o que torna a empresa eficaz em reavaliar tecnologias e sugerir tecnologias novas utilizando os mais diversos conhecimentos sendo que estas ideias corroboram o preconizado por Flatten et al. (2011).

O desempenho merece uma atenção especial foi sua relação não foi validada e há necessidade de aprofundamento dos estudos acerca do tema.

Assim as evidencias permitem inferir que há uma clara associação entre a orientação empreendedora e a capacidade absortiva, porém ambas não influenciam o desempenho de nossas startups. Parece haver falta de ferramental para medirmos o desempenho de startups, especialmente em fases iniciais de suas trajetórias, e os autores sugerem esta como uma das principais conclusões do trabalho, ou seja, o desenvolvimento de escalas que possam ser capazes de identificar traços de sucesso em startups de maneira consistente.

As limitações desta pesquisa estão relacionadas aos poucos estudos profundos sobre o sistema de startups como um todo, visto que a maioria dos trabalhos busca identificar pequena porções da população, característica esta que torna especialmente desafiador o desenvolvimento de uma escala de desempenho capaz de captar a essência da diferenciação de resultados. A variável desempenho foi uma das principais limitações deste trabalho e seguramente merece mais atenção da comunidade científica. Outra limitação foi a invalidação parcial de alguns itens da escala de capacidade absortiva que diziam respeito a aquisição de conhecimento pelos gestores das Startups, e para compartilhar o aprendizado no período da pesquisa percebi que muitos empreendedores não aprendem mais pelas vias tradicionais e formais como cursos de graduação e pós graduação o que nos leva a necessidade de adaptar as novas ferramentas de pesquisa para um aprendizado através do convívio, da troca de ideias e da reconhecimento dos eventos setoriais como novas formas de aquisição de conhecimento.

\section{Bibliografia}

BEAL, D. J.; DAWSON, J. F. On the use of Likert scales in multilevel data: influence on aggregate variables. Organizational Research Methods, v. 10, n. 4, p. 657-672, 2007.

CAMISÓN, C.; FORÉS, B. Knowledge absorptive capacity: New insights for its conceptualization and measurement. Journal of Business Research, v. 63, n. 7, p. 707-715, 2010.

COHEN, W. M.; LEVINTHAL, D. A. A new perspective on learning and innovation. Administrative Science Quarterly, v. 35, n. 1, p. 128-152, 1990a. COHEN, W. M.; LEVINTHAL, D. A. Absorptive Capacity: A New Perspective on Learning and Innovation. Administrative Science Quarterly, v. 35, n. 1, p. 128-152, 1990 b.
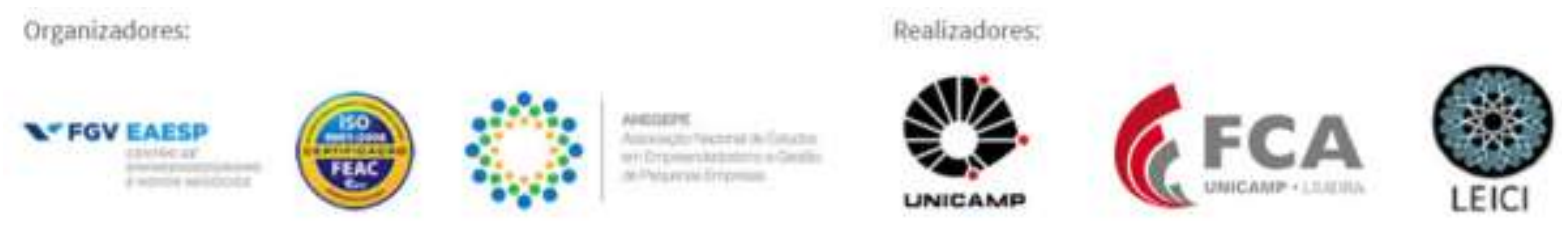
COVIN, J. G.; GREEN, K. M.; SLEVIN, D. P. Strategic Process Effects on the Entrepreneurial Orientation-Sales Growth Rate Relationship. Entrepreneurial Theory and Practice, v. 1, p. 57-81, 2006.

COVIN, J. G.; SLEVIN, D. P. Strategic management of small firms in hostile and benign environments. Strategic Management Journal, v. 10, n. 1, p. 75-87, jan. 1989.

FLATTEN, T. C. et al. A measure of absorptive capacity: Scale development and validation. European Management Journal, v. 29, n. 2, p. 98-116, 2011.

GARCÍA-MUIÑA, F.; NAVAS-LÓPEZ, J. Explaining and measuring success in new business: The effect of technological capabilities on firm results. Technovation, $v$. 27, p. 30-46, 2007.

HAIR, J. F. J. et al. Fundamentos de métodos de pesquisa em Administração. Porto Alegre: Bookman, 2005.

Hair Jr., J.F. et al. (2014). A Primer on Partial Least Squares Structural Equation Modeling (PLS-SEM). Los Angeles: SAGE.

HARVEY, G. et al. Absorptive Capacity in a Non-Market Environment. Public Management Review, v. 12, n. February 2015, p. 77-97, 2010.

Henseler, J., Ringle, C., \& Sinkovics, R. (2009). The Use of Partial Least Squares Path Modeling in International Marketing. Advance in International Marketing, 20, 277-319. http://dx.doi.org/10.1108/S1474-7979(2009)0000020014

HULT, G. T. M.; KETCHEN, D. J.; ARRFELT, M. Strategic supply chain management: Improving performance through a culture of competitiveness and knowledge development. Strategic Management Journal, v. 28, n. 10, p. 1035- 1052, 2007.

LANE, P. J.; LUBATKIN, M. Relative absorptive capacity and interorganizational learning. Strategic Management Journal, v. 19, n. 5, p. 461-477, 1998.

LEDWITH, A. et al. Market Orientation, NPD Performance, and Organizational Performance in Small Firms. Journal of Product Innovation Management, v. 26, n. 996, p. 652- 661, 2009.

LI, Y.; WEI, Z.; LIU, Y. Strategic orientations, knowledge acquisition, and firm performance: The perspective of the vendor in cross-border outsourcing. Journal of Management Studies, v. 47, n. 8, p. 1457-1482, 2010.

LUMPKIN, G. T.; DESS, G. G. Enriching the entrepreneurial orientation construct: A reply to "Entrepreneurial orientation or pioneer advantage. Academy of Management Review, v. 21, n. 3, p. 605-607, 1996.

MALHOTRA, N. K. Pesquisa de Marketing: uma orientação aplicada. Porto Alegre: Bookman, 2001.
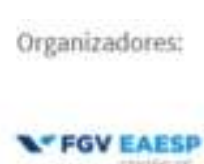
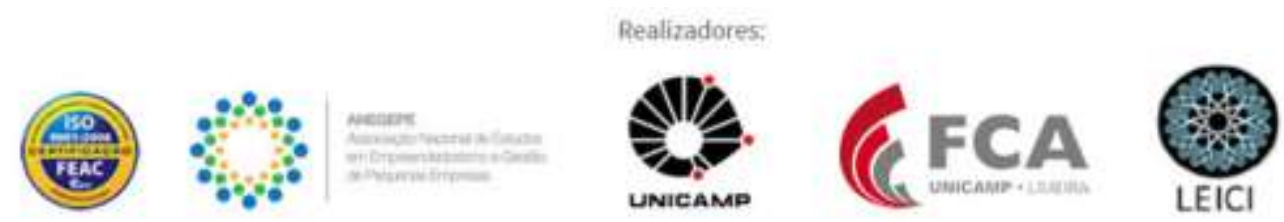
MALLICK, D. N.; SCHROEDER, R. G. An integrated framework for measuring product development performance in high technology industries. Production and Operations Management, v. 14, n. 2, p. 142-158, 2005

MILLER, D. The Correlates of Entrepreneurship in Three Types of Firms. Management Science, v. 29, n. 7, p. 770-791, 1983.

PEGN. Mercado de startups cresce no Brasil e movimenta quase R\$ 2 bi. Disponível em: <http://g1.globo.com/economia/pme/noticia/2014/01/mercado-destartupscresce-no-brasil-e-movimenta-quase-r-2-bi.html>. Acesso em: 7 jul. 2017.

PEÑA, I. Intellectual capital and business start-up success. Journal of Intellectual Capital, v. 3, n. 2, p. 180-198, 2002.

RAUCH, A. etal. Entrepreneurial orientation and business performance: An assessment of past research and suggestions for the future. Entrepreneurship: Theory and Practice, v. 33, n. 3, p. 761-787, 2009.

SILVA, D. (2015). Modelagem de equações estruturais usando o SmartPLS. 17 de abr. 2015. 290 p. Notas de Aula.

TEECE, D. J. Explicating dynamic capabilities: The nature and microfoundations of (sustainable) enterprise performance. Strategic Management Journal, v. 28, n. 13, p. 1319- 1350, 2007.

TODOROVA, G.; DURISIN, B. ABSORPTIVE CAPACITY: VALUING A RECONCEPTUALIZATION. Academy of Management Review, v. 32, n. 3, p. 774786, 1 jul. 2007.

VAN WIJK, R.; VAN DEN BOSCH, F. A. J.; VOLBERDA, H. W. Absorptive Capacity: Taking Stock of its Progress and Prospects. Handbook of Organizational Learning and Knowledge Management, Second Edition, 2011.

VENKATRAMAN, N. Strategic Orientation of Business Enterprises: The Construct, Dimensionality, and Measurement. Management Science, v. 35, n. 8, p. 942-962, 1989.

ZAHRA, S. S. A.; GEORGE, G. Absorptive Capacity: A Review, Reconceptualization, and Extension The Academy of Management Review, 2002. Disponível em: <http://links.jstor.org/sici?sici=03637425(200204)27:2\%3C185:ACARRA\%3E2.0.CO;2$6 \&$ origin $=$ crossref $>$

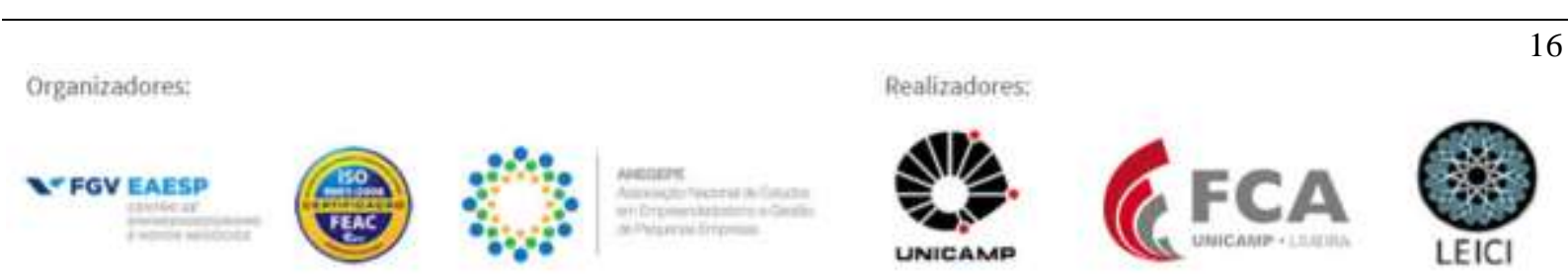

